Note

\title{
Efficacy of Electrolyzed Water As a Primary Cleaning Agent
}

\author{
SATOSHI FUKUZAKI ${ }^{*}$, HIROSHI HIRATSUKA², ATSUHIKO TAKEHARA', \\ KAZUHIRO TAKAHASHI', AND KEN SASAKI ${ }^{2}$
}

1'Industrial Technology Center of Okayama Prefecture, 5301 Haga, Okayama 701-1296, and ${ }^{2}$ Material Science and Engineering, Graduate School of Engineering,

6-20-1 Nakano, Aki-ku, Hiroshima 739-0321, Japan

Received 1 May 2004/Accepted 24 July 2004

\begin{abstract}
Alkaline (AIEW) and acidic electrolyzed water (ACEW) were prepared by the electrolysis of a dilute sodium nitrate solution. The efficacy of AIEW (pH 11.5) in removing the gelatin deposited on stainless steel particles was compared with that of warm deionized water (DIW; pH 5.7) at various temperatures of 20 to $80^{\circ} \mathrm{C}$. The efficiency of the DIW cleaning increased with increasing temperatures from 20 to $70^{\circ} \mathrm{C}$, whereas it decreased to some extent at $80^{\circ} \mathrm{C}$. On the other hand, the efficiency of AIEW cleaning increased with increasing temperatures up to $50^{\circ} \mathrm{C}$, above which it decreased gradually. AlEW cleaning was shown to be by far more effective in removing gelatin than warm DIW cleaning, and its optimum temperature was $50^{\circ} \mathrm{C}$. AcEW cleaning removed calcium hydrogenphosphate deposited on stainless steel particles, depending on the solution $\mathrm{pH}$, and resulted in the modification of the surface charge of stainless steel particles, due to the oxidizing action of nitrate in AcEW.
\end{abstract}

Key words: Electrolyzed water/Primary cleaning/Stainless steel/Gelatin removal/Acid rinse.

In the food industry, products are often biologically contaminated through contact with the surfaces of equipment, shredders, slicers, and cutting boads (Criado et al., 1994; Garg et al., 1990; Klontz et al., 1995). Food ingredients, as well as microorganisms, can spontaneously adsorb onto equipment surfaces during the manufacturing operation. Food residues reduce the effectiveness of disinfectants and give rise to the subsequent growth of microorganisms. Therefore, food residues and living microorganisms on equipment surfaces should be reduced to a large extent by cleaning and disinfecting operations to minimize the risk of cross-contamination and the possibility of foodborne illness.

Gelatin is widely used as a thickening, stabilization, and gelling agent for processed foods and it tends to readily adsorb onto equipment surfaces. In general, the initial step in cleaning surfaces in contact with

${ }^{*}$ Corresponding author. Tel: +81-86-286-9600, Fax : +81$86-286-9630$ gelatin is typically a primary cleaning with warm water (ca. 50 to $60^{\circ} \mathrm{C}$ ). This primary cleaning is critical for removing the bulk of the gelatin deposited on equipment surfaces, and the remaining gelatin is removed, if necessary, by an alkaline detergent. Removal of greater amounts of gelatin in the primary cleaning step would aid further cleaning efforts by reducing detergent loading. On heated surfaces, removal of gelatin becomes more difficult because the dehydration of the gelatin layer may occur together with the depositing of mineral salts.

Recently, electrolyzed water has been receiving attention as a novel disinfectant and cleaning solution. When sodium chloride solution is electrolyzed using an electrolyzer in which the anode and cathode are separated by a membrane, acidic electrolyzed water (AcEW) is generated at the anode site, while alkaline electrolyzed water (AIEW) is generated at the cathode site. AcEW has a bactericidal effect on various types of bacteria (Kim et al., 2000; Koseki and Itoh, 2001; Koseki et al., 2001; Park et al., 2002) and its 
bactericidal activity is quantitatively correlated to the concentration of hypochlorous acid $(\mathrm{HOCl})$ in solution (Nakagawara et al., 1998). On the other hand, AIEW is considerd to be a dilute sodium hydroxide solution and it is useful for the dissolution and dispersion of organic food ingredients on equipment surfaces. Takehara et al. (2001) reported that the efficiency of AIEW cleaning of protein-fouled alumina $\left(\mathrm{Al}_{2} \mathrm{O}_{3}\right)$ particles depended on the solution $\mathrm{pH}$, i.e., the hydroxide ion $\left(\mathrm{OH}^{-}\right)$concentration. The $\mathrm{pH}$ of AIEW is within approximately 11.0 to 11.5 , so that its alkalinity is suitable for the primary cleaning of equipment surfaces fouled with proteins. From the viewpoint of cleaning, AIEW and AcEW are expected to be effective in removing organic and inorganic fouling deposits on equipment surfaces, respectively. However, the efficacies of AIEW and AcEW as cleaning agents are still not fully understood.

The following study was devised to quantitate the efficacy of AlEW versus warm water as a primary cleaning agent for removing the gelatin deposited on stainless steel surfaces. We used sodium nitrate $\left(\mathrm{NaNO}_{3}\right)$ as an electrolyte for the preparation of electrolyzed water because nitrate ions are more congenial to stainless steel than chloride ions. The efficacy of AcEW in removing calcium hydrogenphosphate $\left(\mathrm{CaHPO}_{4}\right)$ deposited on stainless steel particles was also compared with that of dilute a nitric acid solution.

Non-porous $316 \mathrm{~L}$ stainless steel particles were obtained from The Nilaco Corp. (Tokyo). The specific surface area, as determined by the BET method (Fukuzaki et al., 1995b), was $0.11 \mathrm{~m}^{2} / \mathrm{g}$. Gelatin was purchased from Wako Pure Chemical Ind. Ltd. (Osaka). All other chemicals were of analytical grade and were purchased from commercial sources.

AIEW and AcEW were generated by the electrolysis of $0.1 \% \mathrm{NaNO}_{3}$ solution using an electrolyzed water generator (Super Oxseed Labo; Amano Corp, Yokohama). The pHs and ORPs of the AIEW and AcEW obtained were $11.5,-810 \mathrm{mV}$ and $2.3,520 \mathrm{mV}$, respectively. The $\mathrm{pH}$ of AcEW was controlled to be in the $\mathrm{pH}$ range of 1.7 to 2.8 by electrolysis time.

The gelatin solution was prepared by dissolving $0.4 \mathrm{~g}$ of gelatin in $100 \mathrm{ml}$ of deionized water. The $100-$ $\mathrm{ml}$ quantity of the gelatin solution and $20 \mathrm{~g}$ of stainless steel particles were put into $500 \mathrm{ml}$ glass flask. After that, evaporation was caused to occur at $40^{\circ} \mathrm{C}$ with a rotary evaporator (R-124; $\mathrm{BÜCHI}$, Switzerland). The obtained particles with gelatin deposits were transferred into a mortar and gently homogenized. The amount of gelatin deposited on particles was $172 \mathrm{mg} /$ $\mathrm{m}^{2}$.

Stainless steel particles with $\mathrm{CaHPO}_{4}$ deposits were prepared by the precipitation method as described previously (Fukuzaki et al., 2001).

Continuous cleaning of stainless steel particles with gelatin deposits was conducted at 20 to $80^{\circ} \mathrm{C}$ in a glass column $(10 \mathrm{~mm} \phi \times 50 \mathrm{~mm})$ installed vertically, into which a 1-g portion of particles with gelatin deposits were packed. Deionized water (DIW) and AIEW were fed from the bottom of the column at a flow rate of $1.0 \mathrm{ml} / \mathrm{min}$ and eluent fractions were collected. The gelatin concentration of each fraction and the amount of gelatin still remaining on the stainless steel particles after 60-min cleaning were measured: i) by the dye-binding method (Fukuzaki et al., 1995b) and ii) by using a total organic carbon analyzer described previously (Takahashi et al., 2003).

Batchwise cleaning of stainless steel particles with $\mathrm{CaHPO}_{4}$ deposits was conducted by introducing $0.5 \mathrm{~g}$ of the particles and $10 \mathrm{ml}$ of $\mathrm{AcEW}$ or $\mathrm{HNO}_{3}$ solution in a $25-\mathrm{ml}$ glass vial, which was then reciprocally shaken (140rpm) at $40^{\circ} \mathrm{C}$ for $10 \mathrm{~min}$. The amount of calcium ions removed was determined by an inductively coupled plasma spectrometer as described previously (Fukuzaki et al., 1995a).

Curves of gelatin desorption from stainless steel particles were analyzed by the integrated model for two first-order reactions occurring simultaneously (Urano and Fukuzaki, 2002):

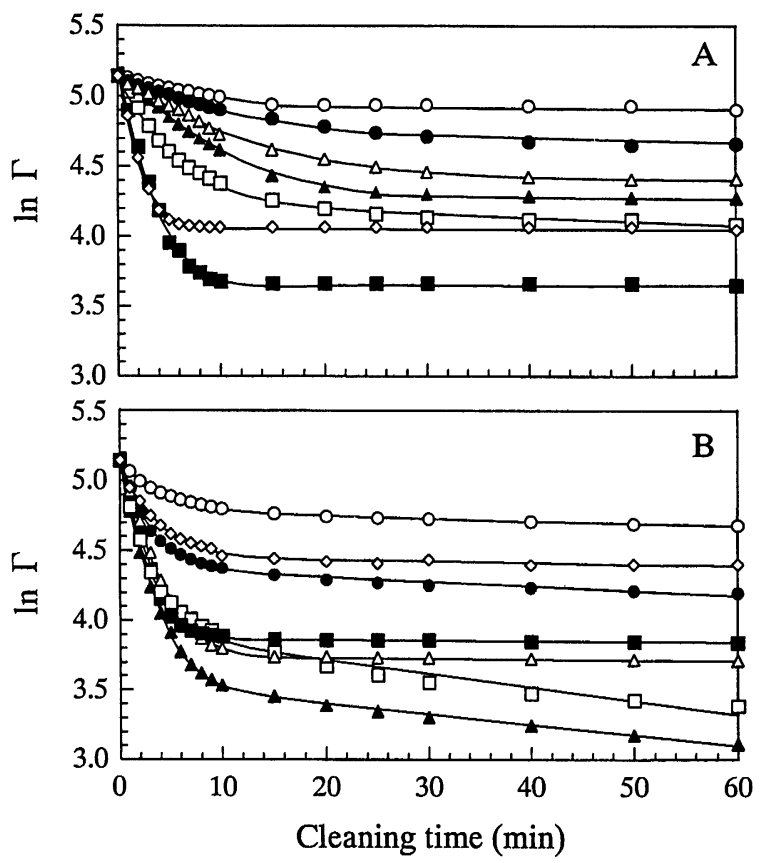

FIG. 1. Effect of temperature on the removal of gelatin deposited on stainless steel particles during DIW cleaning (A) and AlEW cleaning (B). Cleaning was conducted at 20 to $80^{\circ} \mathrm{C}$ in a glass column $(10 \mathrm{~mm} \phi \times 50 \mathrm{~mm})$, into which DIW or AIEW was fed at a flow rate of $1.0 \mathrm{ml} / \mathrm{min}$. Symbols: $\bigcirc, 20^{\circ} \mathrm{C} ; 30^{\circ} \mathrm{C} ; \triangle, 40^{\circ} \mathrm{C} ; \boldsymbol{\Delta}, 50^{\circ} \mathrm{C} ; \square, 60^{\circ} \mathrm{C} ; \square, 70^{\circ} \mathrm{C}$ $\diamond, 80^{\circ} \mathrm{C}$. 
$\ln \Gamma=\ln \left\{\exp \left(\ln \Gamma_{0}^{\dagger}-k^{\dagger} t\right)+\exp \left(\ln \Gamma_{0}^{s}-k^{s} t\right)\right\}(1)$ where $\Gamma$ is the amount of adsorbed gelatin at any given time $t ; \Gamma_{0}{ }^{f}$ and $\Gamma_{0}{ }^{s}$ are assumed to be the amounts of a faster-desorbing gelatin (gelatin ${ }^{f}$ ) and slower-desorbing gelatin (gelatins) at zero time, respectively; $k^{f}$ and $k^{s}$ are the desorption rate constants of gelatin ${ }^{f}$ and gelatins, respectively. The kinetic parameters were calculated by a data-fitting procedure based on a nonlinear least-squares regression method.

Figure 1 compares time course changes in the amount of residual gelatin $(\Gamma)$ in semi-logarithmic graphs during DIW cleaning (panel $A$ ) and AIEW cleaning (panel B) at various temperatures. Each of the solid lines in Fig. 1 was derived from the nonlinear regression fits of eq. 1 . In all the cleaning curves, the rate of gelatin desorption was higher in the initial stage of cleaning, and it decreased gradually as $\Gamma$ decreased toward the later stage of cleaning. In the case of DIW cleaning, the rate of gelatin desorption in the initial stage of cleaning increased markedly with increasing temperatures from 20 to $80^{\circ} \mathrm{C}$, and the amount of gelatin remaining on surfaces after $60 \mathrm{~min}$ of cleaning $\left(\Gamma_{60}\right)$ was the lowest at $70^{\circ} \mathrm{C}$ (Fig. 1A). No significant amount of gelatin was desorbed after 30 min of DIW cleaning at each temperature. In the case of AIEW cleaning, the rate of gelatin desorption in the initial stage increased with increasing temperatures up to $50^{\circ} \mathrm{C}$, whereas it decreased gradually at temperatures above $50^{\circ} \mathrm{C}$ (Fig. 1B). At only 50 and $60^{\circ} \mathrm{C}$ was significant desorption of gelatin continued during $60 \mathrm{~min}$ of AIEW cleaning. $\Gamma_{60}$ was the lowest at $50^{\circ} \mathrm{C}$.

The estimated $k^{\dagger}$ and $k^{s}$ values and $\Gamma_{60}$ at each temperature are summarized in Table 1. The $k^{t}$ and $k^{s}$ val-

TABLE 1. The rate constants of eq. 1 derived from computer analysis and the amount of gelatin remaining on stainless steel particles after $60 \mathrm{~min}$ of cleaning.

\begin{tabular}{ccccc}
\hline $\begin{array}{c}\text { Cleaning } \\
\text { agent }\end{array}$ & $\begin{array}{c}\text { Temp. } \\
\left({ }^{\circ} \mathrm{C}\right)\end{array}$ & $\begin{array}{c}k^{\mathrm{f}} \\
\left(\mathrm{min}^{-1}\right)\end{array}$ & $\begin{array}{c}k^{\mathrm{s}} \\
\left(\mathrm{min}^{-1}\right)\end{array}$ & $\begin{array}{c}\Gamma_{60} \\
\left(\mathrm{mg} / \mathrm{m}^{2}\right)\end{array}$ \\
\hline DIW & 20 & 0.0150 & $<1 \times 10^{-4}$ & 139.4 \\
& 30 & 0.0239 & $<1 \times 10^{-4}$ & 103.5 \\
& 40 & 0.0977 & 0.00017 & 82.4 \\
& 50 & 0.127 & 0.00027 & 73.2 \\
& 60 & 0.233 & 0.00046 & 61.7 \\
& 70 & 0.359 & $<1 \times 10^{-4}$ & 32.0 \\
AIEW & 80 & 0.416 & $<1 \times 10^{-4}$ & 58.4 \\
& 20 & 0.219 & 0.00163 & 108.4 \\
& 30 & 0.327 & 0.00216 & 66.5 \\
& 40 & 0.368 & 0.00337 & 42.1 \\
& 50 & 0.430 & 0.00757 & 22.5 \\
& 60 & 0.385 & 0.00801 & 29.6 \\
& 70 & 0.418 & 0.00057 & 46.4 \\
& 80 & 0.303 & 0.00035 & 81.7 \\
\hline
\end{tabular}

ues apparently reflect the rates of gelatin desorption in the initial stage and middle stage of cleaning, respectively. For DIW cleaning, the $k^{t}$ increased with increasing temperatures, showing apparent temperature-dependence. Judging from the $\Gamma_{60}$ values, however, the efficacy of DIW cleaning at $80^{\circ} \mathrm{C}$ was inferior to that at $70^{\circ} \mathrm{C}$. The $k^{s}$ values obtained from DIW cleaning were very low and therefore it is difficult to discuss the effect of temperature. Both the $k^{\dagger}$ and $k^{s}$ values obtained from AIEW cleaning were higher than those for DIW cleaning at each temperature, and they increased with increasing temperatures from 20 to $50^{\circ} \mathrm{C}$. It was noted that in the case of AIEW cleaning, temperatures at 70 and $80^{\circ} \mathrm{C}$ had a negative effect on the removal of gelatin, which was reflected by lower $k^{s}$ and larger $\Gamma_{60}$ values. These results indicated that AlEW cleaning was by far more effective than warm DIW cleaning and the optimum temperature of AlEW cleaning in removing gelatin was $50^{\circ} \mathrm{C}$.

Figure 2 shows the Arrhenius plots of the $k^{\dagger}$ and $k^{s}$ values. The apparent activation energies, $E_{\mathrm{a}}$, for the $k^{t}$ obtained from DIW cleaning, and for the $k^{t}$ and $k^{s}$ obtained from AIEW cleaning were calculated to be $56.3 \mathrm{~kJ} / \mathrm{mol}\left(20\right.$ to $\left.70^{\circ} \mathrm{C}\right), 17.0 \mathrm{~kJ} / \mathrm{mol}\left(20\right.$ to $50^{\circ} \mathrm{C}$ ), and $36.2 \mathrm{~kJ} / \mathrm{mol}\left(20\right.$ to $60^{\circ} \mathrm{C}$ ), respectively. One estimates that the $k^{\dagger}$ for DIW cleaning increased by a factor of approximately 2.0 for every $10{ }^{\circ} \mathrm{C}$ rise in temperature. In this study, the deposited gelatin (172 $\mathrm{mg} / \mathrm{m}^{2}$ ) formed multiple layers on the stainless steel surface, and therefore gelatin-gelatin interactions dominate the strength forming the gelatin layer. Gelatin is quite similar to a randomly coiled structure with configurational flexibility in aqueous solution (Gouinlock, Jr. et al., 1955). Gelatin is highly hydrated in water and its solubility is higher in warm water than in cold water. It is reasonable that the rate of

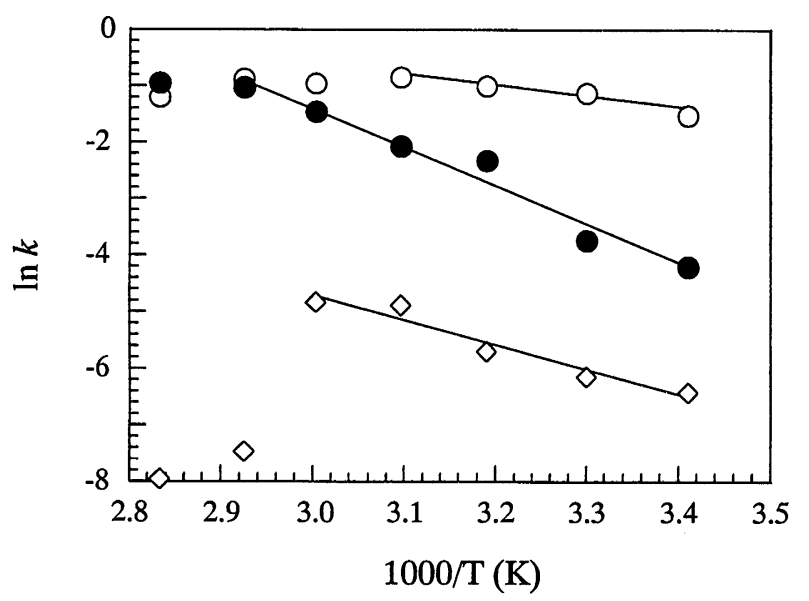

FIG. 2. Arrhenius plots of the $k^{f}$ and $k^{s}$ for AIEW cleaning and of the $k^{\dagger}$ for DIW cleaning. Symbols: $O, k^{\dagger}$ (AIEW); $\diamond, k^{s}(\mathrm{AIEW}) ; 0, k^{f}$ (DIW). 
gelatin desorption by DIW cleaning depended largely on temperature. On the other hand, it was estimated that the $k^{t}$ and $k^{s}$ for AIEW cleaning increased by approximately 1.2 times and by approximately 1.6 times for every $10^{\circ} \mathrm{C}$ rise in temperature, respectively. In the case of AlEW cleaning, the effect of temperature was more reflected in the $k^{s}$ values rather than the $k^{\dagger}$ values. The detergency of AIEW is due to the action of $\mathrm{OH}^{-}$(Takehara et al., 2001). $\mathrm{OH}^{-}$causes deprotonation of acidic amino acid residues on the gelatin molecule, thereby bringing about swelling and hydration of the molecule. As a result, $\mathrm{OH}^{-}$accelerates the dissolution and dispersion of gelatin into AlEW in combination with heat. However, excess heating decelerated the desorption of gelatin, resulting in the larger amount of gelatin remaining on stainless steel surfaces $\left(\Gamma_{60}\right)$. AlEW cleaning at 70 and $80^{\circ} \mathrm{C}$ gave extremely low $k^{s}$ and large $\Gamma_{60}$ values. A similar phenomenon was also observed in the case of DIW cleaning at $80^{\circ} \mathrm{C}$. It is conceivable that AlEW cleaning $(\mathrm{pH} 11.5)$ at high temperatures might give rise to the heat-denaturation of gelatin molecules and lead to the formation of a firmly coherent gelatin layer on stainless steel surfaces. It is presumed that the cohesion of residual gelatin would depend on the $\mathrm{pH}$ of the cleaning solution and temperature. Although the mechanism by which gelatin removal is decelerated during AIEW cleaning at elevated temperatures is unknown, it is of interest that the optimum AIEW cleaning of gelatin-deposit stainless steel surfaces occurs at $50^{\circ} \mathrm{C}$.

Figure 3 shows the effects of the $\mathrm{pH}$ of the $\mathrm{HNO}_{3}$ solution and AcEW on the efficiency of the removal of

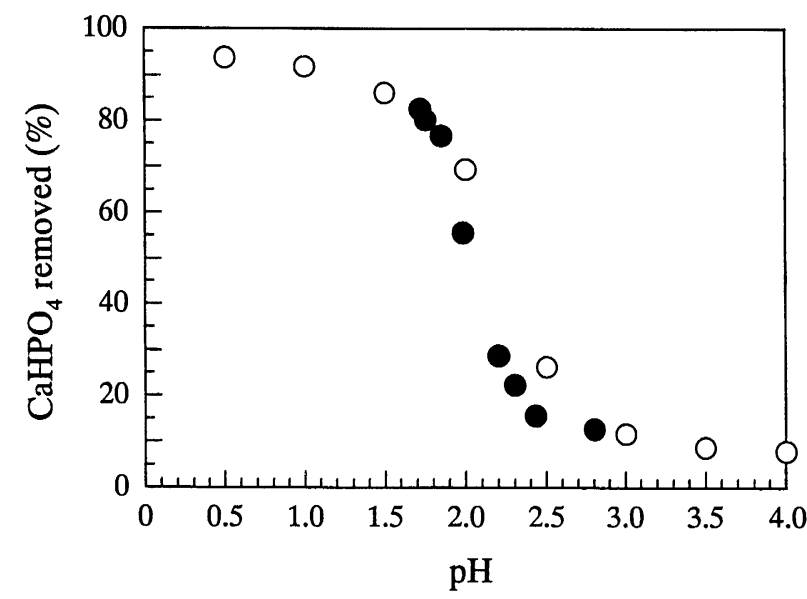

FIG. 3. Effect of $\mathrm{pH}$ on the removal of $\mathrm{CaHPO}_{4}$ deposits on stainless steel particles during AcEW cleaning. Cleaning was conducted in a $25-\mathrm{ml}$ glass vial, containing $0.5 \mathrm{~g}$ of stainless steel particles with $\mathrm{CaHPO}_{4}$ deposits and $10 \mathrm{ml}$ of AcEW or $\mathrm{HNO}_{3}$ solution, at $40^{\circ} \mathrm{C}$ for $10 \mathrm{~min}$ in a batchwise manner. Symbols: $\mathrm{O}, \mathrm{HNO}_{3}$ solution; $\mathrm{AcEW}$.
$\mathrm{CaHPO}_{4}$ from stainless steel particles. In the case of cleaning with the $\mathrm{HNO}_{3}$ solution, the efficiency of $\mathrm{CaHPO}_{4}$ removal increased gradually with decreasing $\mathrm{pH}$ and reached about $94 \%$ at $\mathrm{pH} 0.5$. The relationship between the efficiency of $\mathrm{CaHPO}_{4}$ removal and $\mathrm{pH}$ obtained for AcEW cleaning almost coincided with that obtained for $\mathrm{HNO}_{3}$ cleaning over the $\mathrm{pH}$ range of 1.7 to 2.8. These results indicated that the efficacy of AcEW in removing $\mathrm{CaHPO}_{4}$ from stainless steel particles depended on $\mathrm{pH}$, i.e., proton concentration, and the $\mathrm{pH}$ required for good cleaning is less than at least 2. Therefore, the application of AcEW is suitable for acid rinse rather than acid cleaning.

When stainless steel particles were washed with AcEW ( $p H$ 2.3) containing nitric acid for $2 \mathrm{~h}$, the apparent point of zero charge was lowered from 9.4 (non-rinsed particles) to $6.7 \mathrm{in} \mathrm{pH}$ with a decrease in the positive surface charge (data not shown). $\mathrm{HNO}_{3}$ treatment of stainless steel is reported to give smaller ratios of oxygen in $\mathrm{M}-\mathrm{OH}$ to the total amount of oxygen (oxygen in $\mathrm{M}-\mathrm{OH}$ plus oxygen in $\mathrm{M}-\mathrm{O}-\mathrm{M}$ ) in the passive films (Fukuzaki et al., 2001). Lowering the degree of surface hydroxylation results in a decrease in the positive surface charge of stainless steel, thereby reducing the adsorption affinity of proteins and acidic polysaccharides (Fukuzaki et al., 2001; Takehara and Fukuzaki, 2002).

In this study, $\mathrm{NaNO}_{3}$ was used as an electrolyte instead of $\mathrm{NaCl}$ for the preparation of AlEW and AcEW. It is thought that the kind of electrolyte has no effect on the removal of gelatin during AIEW cleaning because the efficiency of the alkali cleaning of proteinfouled solid surfaces depends largely on $\mathrm{OH}^{-}$ concentration. On the other hand, nitrate ions are practically more congenial to stainless steel than chloride ions. In the dairy industry, an acid rinse (ca. $40^{\circ} \mathrm{C}$ ) is applied after organic soils are thoroughly removed by chlorinated alkaline detergent cleaning. The advantages of the daily acid rinse include the prevention of mineral deposits from water, neutralization of chlorine residues, and reduction of the $\mathrm{pH}$ of the equipment surface which prevent bacterial growth (Mitchell, 1981). AcEW containing nitric acid appears to be available for the acid rinse of stainless steel surface from the viewpoints of descaling, surface modification, and neutralization of alkaline residues after AIEW cleaning.

\section{REFERENCES}

Criado, M.-T., Suárez, B., and Ferreirós, C. M. (1994) The importance of bacterial adhesion in the dairy industry. Food Technol., 48,123-126.

Fukuzaki, S., Nishio, N., and Nagai, S. (1995a) High rate 
performance and characterization of granular methanogenic sludges in upflow anaerobic sludge blanket reactors fed with various defined substrates. J. Ferment. Bioeng., 79, 354-359.

Fukuzaki, S., Urano, H., and Nagata, K. (1995b) Adsorption of protein onto stainless-steel surfaces. J. Ferment. Bioeng., 80, 6-11.

Fukuzaki, S., Urano, H., Hiramatsu, M., and Takehara, A. (2001) Surface treatment and facilitated cleaning of stainless steel by ozonized air. Biocontrol Sci., 6, 95-101.

Garg, N., Churey, J. J., and Splittstoesser, D. F. (1990) Effect of processing conditions on the microflora of freshcut vegetables. J. Food. Prot., 53, 701-703.

Gouinlock, Jr., E. V., Flory, P. J., and Scheraga, H. A. (1955) Molecular configuration of gelatin. J. Polymer Sci ., 16, 383-395.

Kim, C., Hung, Y.-C., and Brackett (2000) Roles of oxidation-reduction potential in electrolyzed oxidizing and chemically modified water for the inactivation of foodrelated pathogens. J. Food Prot., 63, 19-24.

Klontz, K. C., Timbo, B., Fein, S., and Levy, A. (1995) Prevalence of selected food consumption and preparation behaviors associated with increased risks of foodborne disease. J. Food Prot., 58, 927-930.

Koseki, S., and Itoh, K. (2001) Prediction of microbial growth in fresh-cut vegetables treated with acidic electro- lyzed water during storage under various temperature conditions. J. Food Prot., 64, 1935-1942.

Koseki, S.; Yoshida, K., Isobe, S., and Itoh, K. (2001) Decontamination of lettuce using acidic electrolyzed water. J. Food Prot., 64, 652-658.

Mitchell, T. (1981) Cleaning of CIP systems. Dairy Food Sanit., 1, 292-293.

Nakagawara, S., Goto, T., Nara, M., Ozawa, Y., Hotta, K., and Arata, Y. (1998) Spectroscopic characterization and the $\mathrm{pH}$ dependence of bactericidal activity of the aqueous chlorine solution. Anal. Sci., 14, 691-698.

Takahashi, K., Koike, K., and Fukuzaki, S. (2003) Comparison of the efficacies of gaseous ozone and sodium hypochlorite in cleaning stainless steel particles fouled with proteins. Biocontrol. Sci., 8, 87-91.

Takehara, A., Urano, H., and Fukuzaki, S. (2001) Cleaning of alumina fouled with bovine serum albumin by the combined use of gaseous ozone and alkaline electrolyzed water. Biocontrol. Sci., 6, 103-106.

Takehara, A., and Fukuzaki, S. (2002) Effect of the surface charge of stainless steel on adsorption behavior of pectin. Biocontrol. Sci., 7, 9-15.

Urano, H., and Fukuzaki, S. (2002) Kinetic study of desorption of two soil species of bovine serum albumin from alumina during alkali elution process. J. Colloid Interface Sci., 252, 284-289. 